\title{
ANALISIS PENGENAAN TARIF PAJAK PROGRESIF PADA PAJAK KENDARAAN BERMOTOR THE FOUR MAXIMS(STUDI KASUS SAMSAT KABUPATEN PASAMAN BARAT PROVINSI SUMATRA BARAT)
}

\author{
Muammar Khaddafi ${ }^{1}$, Annesa Dianty Darwin ${ }^{2}$ \\ ${ }^{1,2}$ Prodi Akuntansi Fakultas Ekonomi dan Bisnis Universitas Malikussaleh Lhokseumawe \\ khaddafi@unimal.ac.id
}

\begin{abstract}
This study was conducted to determine the imposition of a progressive tax rate on motor vehicle taxes based on The Four Maxims in Pasaman Barat Regency, Sumatra Barat. The method used in this study was a qualitative descriptive method. The type of data used in this study was primary and secondary data. Data collection techniques in this study were interviews, observations, and documentation. The purpose of this study was to determine how to impose a progressive tax rate on motorized vehicle tax based on four principles of tax collection. The results show that the tax principle as still appropriate and relevant to be applied, namely the principles of tax collection proposed by Adam Smith, which are equality, legal certainty, the convenience of payment, and principles efficiency (economic of collection).
\end{abstract}

\section{Keywords: Motor Vehicle Tax, Progressive Taxation Rates, Four Maxims.}

\section{PENDAHULUAN}

Pajak progresif merupakan pajak dengan sistem pemungutannya dengan cara menaikkan persentase kena pajak yang harus dibayar sesuai dengan kenaikkan objek pajak. Pajak progresif kendaraan bermotor dikabupaten pasaman barat mulai diterapkan pada 1 januari 2013 dan mulai dijalankan pada awal tahun 2013.Penerapan pajak progresif ini diharapkan dapat menekan jumlah kendaraan bermotor serta meningkatkan Pendapatan Asli Daerah. Namun karena masih banyak dari wajib pajak yang belum mengerti sepenuhnya tentang penerapan pajak progresif ini, menyebabkan terjadinya permasalahan pada saat warga akan melakukan pembayaran pajak kendaraan bermotor. Mereka harus membayar lebih besar yang disebabkan jumlah kendaraan yang terdaftar atas nama warga tersebut meskipun kendaraan tersebut sudah tidak dimilikinya lagi. Ini terjadi karena warga yang telah menjual kendaraannya, namun kendaraan tersebut masih atas namanya sehingga dikenakan pajak progressif atas kendaraan yang sudah tidak dimilikinya lagi.

Tabel 1

Data Jumlah Kendaraan Bermotor SAMSAT Kabupaten Pasaman Barat

\begin{tabular}{|c|c|}
\hline Tahun & Jumlah (unit) \\
\hline 2012 & 38,461 \\
\hline 2013 & 37,734 \\
\hline 2014 & 36,727 \\
\hline 2015 & 36,705 \\
\hline 2016 & 36,515 \\
\hline 2017 & 35,637 \\
\hline
\end{tabular}

Sumber: SAMSAT Kabupaten Pasaman Barat,2018

Dari data diatas dapat dilihat jumlah unit kendaraan bermotor dari tahun ke tahun. Pada tahun 2012 sebelum diterapkannya pajak progresif, terdapat 38,461 unit kendaraan 
bermotor diKabupaten Pasaman Barat, namun setelah diterapkannya pajak progresif kendaraan bermotor pada tahun 2013, terjadi penurunan jumlah kendaraan bermotor, dan terus menurun hingga akhir tahun 2017. Setelah diberlakukannya pajak progresif ini, masih banyak masyarakat yang tidak nyaman dengan penerapan pajak progresif

tersebut, dikarenakan mereka membayar lebih banyak dari yang seharusnya, ini disebabkan

\section{TINJAUAN PUSTAKA}

\section{Dasar-Dasar Pajak \\ Pengertian Pajak}

Menurut Waluyo (2011):"Pajak adalah iuran kepada Negara (yang dapat dipaksakan) yang terutang oleh yang wajib membayarnya menurut peraturan-peraturan, dengan tidak mendapat prestasi kembali, yang langsung dapat ditunjuk, dan yang gunanya adalah untuk mebiayai pengeluaran umum berhubungan dengan tugas Negara untuk menyelenggarakan pemerintahan".

\section{Fungsi Pajak}

Pajak merupakan sumber penerimaan dari Negara yang mempunyai fungsi (Mardiasmo 2011), yaitu :

1)Fungsi anggaran (budgetair) sebagai sumber dana bagi pemerintah, untuk membiayai pengeluaran-pengeluarannya.

2)Fungsi mengatur (regulerend) sebagai alat pengatur atau melaksanakan pemerintah dalam bidang sosial ekonomi.

\section{Syarat Pemungutan Pajak}

Syarat pemungutan pajak menurut Mardiasmo (2013):

1. Pemungutan pajak harus adil(syarat keadilan)

2. Pemungutan pajak harus berdasarkan Undang-Undang(syarat yuridis)

3. Tidak mengganggu perekonomian (syarat ekonomis)

4. Pemungutan pajak harus efisien

5. Pemungutan pajak harus sederhana

\section{Teori yang dapat mengatur pemungutan} pajak

Teori yang menjelaskan tentang pemberian hak kepada Negara untuk memungut pajak menurut Mardiasmo (2011):

1. Teori asuransi Negara melindungi keselamatan jiwa, harta benda,dan hak-hak rakyatnya. karena kurangnya informasi yang detail mengenai pajak progresif ini kendaraan bermotor ini.

Berdasarkan uraian tersebut diatas, maka peneliti mengambil judul: "Analisis Pengenaan Tarif Pajak Progresif Pada Pajak Kendaraan Bermotor Berdasarkan The Four Maxims (Studi Kasus SAMSAT Kab.Pasaman Barat Provinsi Sumatra Barat)".

Oleh karena itu rakyat harus membayar pajak yang diibaratkan sebagai suatu premi asuransi karena memperoleh jaminan perlindungan tersebut.

2. Teori kepentingan

Beban pajak kepada rakyat didasarkan pada kepentingan masing-masing orang.Semakin besar kepentingan seseorang terhadap Negara, maka semakin tinggi pajak yang harus dibayar.

3. Teori daya pikul

Beban pajak untuk semua orang harus sam beratnya, artinya pajak harus dibayar sesuai dengan daya pikul masing-masing orang.

4. Teori Bakti

Dasar keadilan pemungutan pajk terletak pada hubungan rakyat dengan negaranya, sebagai warga Negara yang berbakti, rakyat harus selalu menyadari bahwa pembayaran pajak adalah suatu kewajiban.

5. Teori azas daya beli

Dasar keadilan terletak pada akibat pemungutan pajak.

Sistem pemungutan pajak

System pemungutan pajak dibagi tiga:

1. Official Assessement System

Merupakan sistim pemungutan pajak yang member wewenang kepada pemerintah umtuk menentukan besarnya pajak terutang.

2. Self Assessement System

Merupakan sistim pemungutan pajak yang member wewenang kepada wajib pajak untuk menghitung, membayar dan melaporkan sendiri besarnya pajak yang harus dibayar.

3. Withholding System

Merupakan sistim pemungutan pajak yang member wewenang kepada pihak ketiga untuk memotong, memungut besarnya pajak yang terutang oleh wajib pajak.

\section{Hambatan Pemungutan Pajak}


Menurut Mardiasmo (2013), ha,batan pemungutan pajak dapat dikelompokkan sebagai berikut:

1. Perlawanan Pasif

Masyarakat tidak mau (pasif) dalam membayar pajak.

2. Perlawanan Aktif

Meliputi semua usaha dan perbuatan secara langsung ditujukan kepada fiskus dengan tujuan untuk menghindari pajak.

\section{Tarif Pajak Kendaraan Bermotor}

Menurut Mardiasmo (2013), tarif kendaraan bermotor adalah:

1. $1,5 \%$ untuk kepemilikan kendaraan bermotor pribadi dan badan.

2. $1,0 \%$ untuk kendaraan bermotor angkutan umum

3. $0,5 \%$ untuk kendalaan ambulance, pemadam kebakaran, sosial keagamaan dan instansi pemerintah.

\section{Wajib Pajak}

Menurut Undang-Undang No. 28 Tahun 2007 pasal 1 ayat (1) tentang Tata Cara Perpajakan bahwa yang dimaksud dengan wajib pajak adalah sebagai berikut:

"Wajib Pajak adalah orang pribadi atau badan yang menurut ketentuan peraturan perundang-undangan perpajakn ditentukan untuk melakukan kewajiban perpajakan, termasuk pemungut pajak atau pemotong pajak tertentu."

\section{Pajak Daerah}

\section{Pengertian Pajak Daerah}

Menurut Undang-Undang No. 28 Tahun 2009 Tentang Pajak Daeran dan Retribusi Daerah:

"Pajak daerah, yang selanjutnya disebut Pajak adalah kontribusi wajib kepada daerah yang terutang oleh orang pribadi atau badan yang bersifat memaksa berdasarkan UndangUndang, dengan tidak mendapatkan imbalan secara langsung dam digunakan untuk keperluan daerah bagi sebesar-besarnya kemakmuran rakyat."

\section{Ciri-Ciri Pajak Daerah}

Ciri-Ciri Pajak Daerah antara lain:

1. Pajak Daerah berasal dari pajak Negara yang diserahkan kepada daerah sebagai pajak daerah.

2. Penyerahan dilakukan berdasarkan Undang-Undang.
3. Pajak Daerah dipungut oleh daerah berdasarkan kekuatan UndangUndang atau kegiatan hukum lainnya.

4. Hasil pemungutan pajak daerah dipergunakan untuk membiayai penyelenggaraan urusan rumah tangga daerah atau untuk membiayai pengeluaran daerah sebagai badan hukum public.

\section{Pajak Kendaraan Bermotor}

\section{Pengertian Pajak Kendaraan Bermotor}

Pajak Kendaraan Bermotor (PKB) adalah pajak atas kepemilikan atau penguasaan kendaraan bermotor, yaitu kendaraan beroda dua atau lebih beserta gandengannya yang digunakan di semua jenis jalan darat dan digerakkan oleh peralatan teknik berupa motor atau peralatan lainnya yang berfungsi untuk mengubah suatu sumber daya energy tertentu menjadi tenaga gerak kendaraan bermotor yang bersangkutan, termasuk alat-alat besar yang bergerak.

\section{Subjek Pajak Kendaraan Bermotor}

Subjek pajak kendaraan bermotor adalah orang pribadi atau badan yang memiliki dan/atau menguasai kendaraan bermotor (Pasal 4 ayat (1) UU PDRD).

Dasar Pengenaan, Tarif dan Cara Perhitungan Pajak Kendaraan Bermotor Berdasarkan Perda Provinsi Sumatra Barat No. 4 Tahun 2011 tentang Pajak Daerah Berdasarkan Perda Provinsi Sumatera Barat No. 4 Tahun 2011 tentang pajak daerah, dasar pengenaan, tarif dan cara perhitungan pajak kendaraan bermotor adalah sebagai berikut:

Dalam pasal 6 angka (1) dasar pengenaan PKB adalah:

a. Berdasarkan Nilai Jual Kendaraan Bermotor

b. Bobot yang secara relatif tingkat kerusakan jalan dan/atau pencemaran lingkungan akibat penggunaan kendaraan bermotor.

Dalam pasal 7, tarif PKB pribadi ditetapkan sebagai berikut:

a. Untuk kepemilikan pertama sebesar $1,5 \%$

b. Untuk kepemilikan kedua dikenakan tarif progresif sebesar $2 \%$

c. Untuk kepemilikan ketiga sebesar $2,5 \%$

d. Untuk kepemilikan keempat sebesar 3\%

e. Untuk kepemilikan kelima dan seterusnya akan dikenakan sebesar $3,5 \%$. 


\section{Pajak Progresif \\ Pengertian Pajak Progresif}

Menurut Koswara (2000), pajak progresif adalah pajak diterapkan bagi kendaraan pribadi baik roda dua dan roda empat dengan nama pemilik dan alamat tempat tinggal yang sama.

\section{Konsep The Four Maxims}

Asas-asa pemungutan Pajak Kendaraan Bermotor oleh Adam Smith yaitu (Diana Sari,2013)

1. Asas Keadilan (Asas Equality) setiap wajib pajak harus dberlakukan berdasarkankan tarif pajak progresif pada pajak kendaraan bermotor.

2. Asas Kepastian Hukum(Asas Certainty)dasar pengenaan tarif pajak bermotor dipungut berdasarkan undang-undang.

3. Saat yang paling tepat dalam pembayaran pajak(Asas convenience of payment)sesuai dengan tanggal dimana wajib pajak membeli pajak kendaraan bermotor yang akan dikenai pajak.

4. Asas Efisiensi (Asas Efficiency) Berdasarkan mekanisme samsat yang ada.dimana terdapat fasilitas yang memadai dalam rangka menunjang pemungutan pajak yang seminim mungkin.

\section{Penelitian Terdahulu}

Sebagai pertimbangan dalam penelitian ini berikut dicantumkan penelitian yang dilakukan sebelumnya.

Penelitian yang dilakukan oleh Fabrianti (2011) dalam penelitiannya mengenai Analisis Sistem Pengendalian Pemungutan Pajak Kendaraan Bermotor dalam Peningkatan PAD pada Dispenda Kota Singkawang, Hasil Penelitian ini adalah system pemungutan pajak kendaraan bermotor di dispenda kota singkawang sudah efektif dengan adanya bagian-bagian yang terlihat lebih dari pada satu bagian, seperti bagian pengambilan formulir, danpengisian formulir, penetapan PKB dan penetapan SWDKLLJ dan bagian pembayran dan penyerahan. Selain itu formulir yang digunakan serta rangkap distribusinya sudah dijalankan dengan baik.

Nugraha pada tahun 2012 dengan judul Penerapan Pajak Progresif Terhadap Wajib Pajak Kendaraan Bermotor Berdasarkan Peraturan Daerah Jawa Timur No. 9 Tahun 2010 tentang Pajak Daerah. Hasil penelitian tersebut adalah masih banyak masyarakat yang menjual kendaran bermotornya, namun belum melakukan balik nama, sehingga penjual tersebut masih terdaftar sebagai pemilik kendaraan yang sudah dijualnya tersebut, dan apabila dia membeli kendaraan baru maka dia akan dikenakan pajak progresif.

Penelitian yang dilakukan Dianita (2012) yang berjudul Pengaruuh Pelayanan terhadap Kepuasaan Masyarakat terhadap Pelayanan Pajak Progresif Kendaraan Bermotor di Samsat Kota Bandung.Hasil penelitiannya adalah pelayanan pembayaran progresif kendaraan bermotor berpengaruh signifikan terhadap kepuasan masyarakat yaitu sebesar 0,629 atau 62,9\%.

Penelitian yang dilakukan Rudi Irwanto (2015) yang berjudul Analisis Penerapan Pajak Progresif terhadap Wajib Pajak Kendaraan Bermotor (Studi Kasus Samsat Kota Makassar).Hasil peneitiannya menunjukkan bahwa setelah diberlakukannya pajak progresif, persentase penerimaan pajak kendaraan bermotor mengalami penurunan.

Penelitian Adi (2012) dengan judul Penerapan Pajak Progresif Kendaraan Bermotor Dalam Upaya Meningkatkan Pendapatan Asli Daerah (Up3ad) Samsat Surakarta.Dalam penelitian ini ditemukan bahwa belum dipisahkannya subjek dan objek pajak progresif sehingga belum dapat diketahui jumlah penerimaan dari pajak progresif itu sendiri.

\section{METODE PENELITIAN}

\section{Jenis Penelitian}

Jenis penelitian dengan menggunakan metode analisis data kualitatif yang sifatnya deskriptif, yaitu dengan prosedur pemecahan masalah dengan cara memaparkan semua data yang diperoleh dari hasil observasi yang kemudian dianalisis lalu ditarik kesimpulan.

\section{Objek Penelitian}

Objek dari penelitian ini adalah Samsat Kota Padang, karena kantor Samsat ini melayani administrasi tentang Pajak Kendaraan Bermotor untuk wilayah Kota Padang dan telah menerapkan pajak progresif.

\section{Jenis dan Sumber Data}

Jenis data yang digunakan dalam penelitian ini adalah:

1. Data Kualitatif, berupa hasil wawancara terhadap objek penelitian.

2. Data Kualitatif, berupa data tarif pajak progresif.

Sumber data dalam penelitian ini yaitu:

1. Data Primer, diperoleh secara langsung dari hasil dokumentasi dan 
wawancara oleh peneliti terhadap objek penelitian.

2. Data Sekunder, data yang diperoleh secara tidak langsung dengan cara memperoleh dari kepustakaan, catatan, jurnal dan arsip perusahaan, berupa rekapitulasi penerimaan pajak kendaraan bermotor.

\section{Teknik Pengumpulan Data}

Teknik pengumpulan data dalam penelitian ini antara lain:

1. Studi Kepustakaan

Yaitu pengumpulan data dengan membaca literatur-literatur yang berhubungan dengan masalah yang diambil.

2. Penelitian Lapangan

Penelitian lapangan berupa:

a. Wawancara, merupakan percakapan dua orang, yang dimulai oleh pewawancara dengan tujuan memperoleh keterangan sesuai dengan penelitian dan dipusatkan olehnya olehnya pada isi dan dititik beratkan tujuan-tujuan deskripsi, prediksi dan penjelasan sistematik mengenai penelitian tersebut.

b. Dokumentasi, merupakan suatu cara pengumpulan data dengan menggunakan dokumentasi dari Samsat Kota Padang.

\section{Metode Analisis Data}

Dalam penelitian ini, metode analisis data yang digunakan adalah Deskriptif Analisis, menurut Sugiyono (2007), "Deskripsi analisis yaitu suatu metode yang dapat digunakan untuk meneliti sekelompok manusia, suatu kondisi, sistim pemikiran ataupun suatu peristiwa pada masa sekarang."

\section{Hasil Penelitian dan Pembahasan Gambaran Umum dan Lokasi Penelitian Sejarah Samsat di Indonesia}

System Administrasi Manunggal Satu Atap(Samsat) adalah suatu sistim kerjasama secara terpadu antara POLRI, Dispenda Provinsi dan PT. Jasa Raharja (Persero) dalam pelayanan untuk menerbitkan STNK dan TNKB yang dikaitkan dengan pemasukan uang ke kas Negara baik melalui pajak kendaraan bermotor, BBNKB, dan SWDKLLJ yang dilaksanakan pada satu kantor yaitu Kantor Bersama Samsat.

\section{Gambaran Umum Mengenai Samsat Kab.pasaman Barat}

Samsat Kab.Pasaman Barat bertugas mengurus administrasi perpajakan kendaraan bermotor di Kab.Pasaman Barat.Berada di Jln. M. Natsir No.61 Telp (0753) 7464029 Fax.(0753) 7464029Simp.Ampek Pasaman barat yang didirikan pertama kali tahun 2007 yang pertama kali diketua oleh Harfianda Harman,S.H Visi dan Misi Samsat Kota Padang:
a. Visi
"Terwujudnya pelayanan cepat, tepat dan akurat berbasis teknologi bersih." informasi menuju pemerintahan yang
b. Misi
1. Meningkatkan kualitas pelayanan kepada masyarakat
2. Meningkatkan sumber daya manusia
3. Meningkatkan identifikasi dan keamanan kepemilikan kendaraan bermotor
4. Meningkatkan pelayanan daerah dan pusat

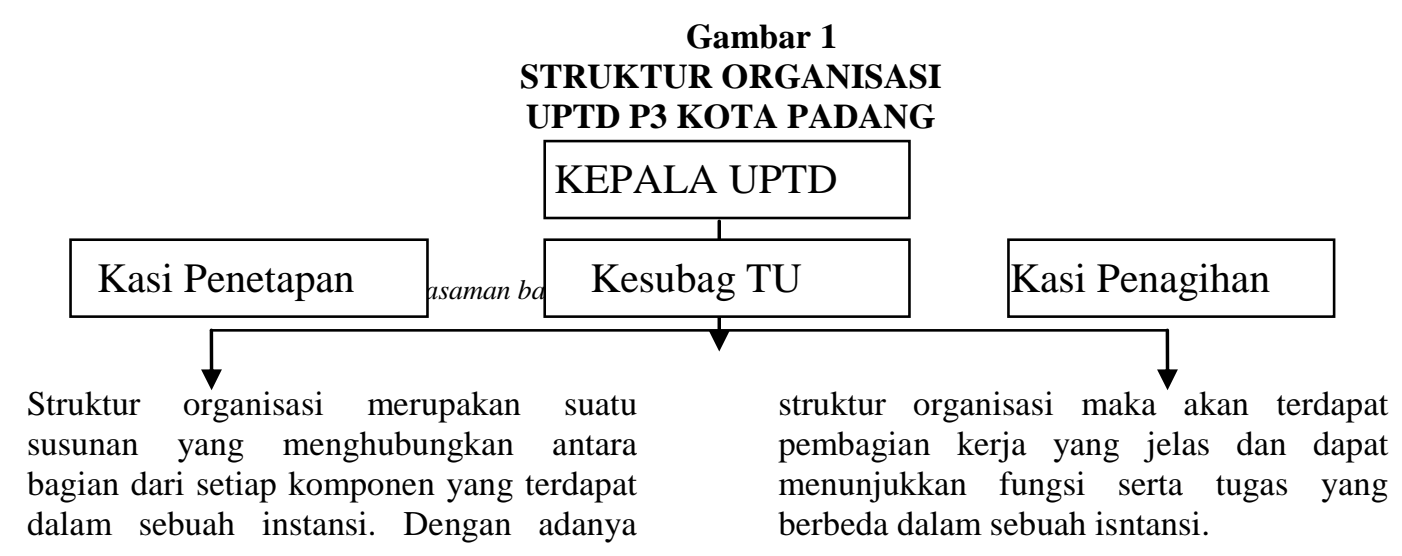




\section{HASIL PENELITIAN}

Pengenaan Tarif Pajak Progresif pada Kendaraan Bermotor Provinsi di Kabupaten Pasaman Barat penentuan urutan Pajak Progresif

Tabel 2

Target Penerimaan Pajak Kendaraan Bermotor Provinsi di Kabupaten Pasaman Barat

\begin{tabular}{|l|c|c|c|}
\hline \multirow{2}{*}{ No } & \multirow{2}{*}{ Target Tahun } & \multicolumn{2}{|c|}{ Jenis Penerimaan } \\
\cline { 3 - 4 } & & $\mathrm{Rp} 14.018 .931 .000$ & $\mathrm{Rp} 195.393 .000$ \\
\hline 1. & 2013 & $\mathrm{Rp} 14.566 .188 .000$ & $\mathrm{Rp} 173.993 .000$ \\
\hline 2. & 2014 & $\mathrm{Rp} 16.112 .000 .000$ & $\mathrm{Rp} 211.021 .300$ \\
\hline 3. & 2015 & $\mathrm{Rp} 18.508 .740 .800$ & $\mathrm{Rp} \mathrm{305.054.000}$ \\
\hline 4. & 2016 & $\mathrm{Rp} \mathrm{20.765.473.050}$ & $\mathrm{Rp} 415.707 .760$ \\
\hline 5. & 2017 &
\end{tabular}

Sumber : Samsat Provinsi di Kabupaten Pasaman Barat, 2018

Berdasarkan Tabel 2 diatas terlihat

bahwa target penerimaan pajak daerah provinsi di kabupaten Pasaman Barat selama
5 tahun yaitu mulai tahun 2013-2017 di targetkan meningkat.

Gambar 2 Persentase Target Penerimaan Tarif Pajak Progresif PKB tahun 2013-2017

\section{Persentase Target Penerimaan Tarif Pajak Progresif PKB tahun 2013-2017}

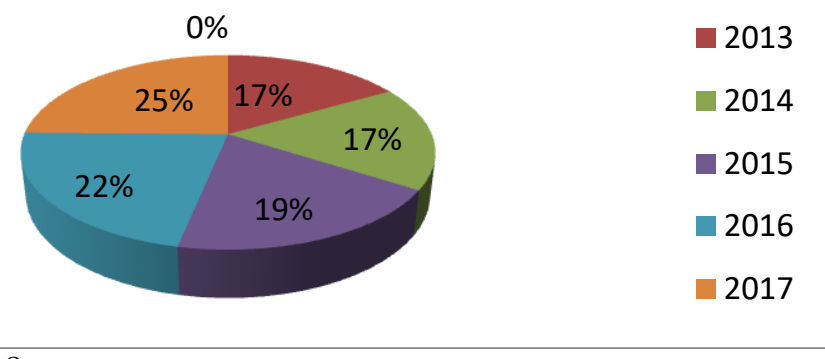

sumber : Diolah Peneliti, 2018

Dari Gambar 2 diatas dapat dijelaskan bahwa persentase penerimaan Tarif Pajak Progresif PKB pada tahun 2013 sebesar $17 \%$ sedangkan pada tahun 2014 sebesar 17\%, Tabel 3

Realisasi Penerimaan Pajak Kendaraan Bermotor Provinsi di Kabupaten Pasaman Barat

\begin{tabular}{|l|c|c|c|}
\hline \multirow{2}{*}{ No } & \multirow{2}{*}{ Tahun Realisasi } & \multicolumn{2}{|c|}{ Jenis Penerimaan } \\
\cline { 3 - 4 } & & PKB & BBNPKB \\
\hline 1. & 2013 & $\mathrm{Rp} 14.740 .279 .300$ & $\mathrm{Rp} \mathrm{200.329.500}$ \\
\hline 2. & 2014 & $\mathrm{Rp} 16.270 .280 .550$ & $\mathrm{Rp} \mathrm{207.133.300}$ \\
\hline 3. & 2015 & $\mathrm{Rp} 17.831 .466 .000$ & $\mathrm{Rp} \mathrm{238.486.950}$ \\
\hline 4. & 2016 & $\mathrm{Rp} 19.982 .338 .400$ & $\mathrm{Rp} \mathrm{328.359.400}$ \\
\hline 5. & 2017 & $\mathrm{Rp} \mathrm{20.765.473.050}$ & $\mathrm{Rp} \mathrm{415.707.760}$ \\
\hline
\end{tabular}

Sumber : Samsat Provinsi di Kabupaten Pasaman Barat, 2018 sedangkan pada tahun 2015 sebesar 19\%, sedangkan pada tahun 2016 sebesar 22\%, sedangkan tahun 2017 sebesar $25 \%$. 
Berdasarkan Tabel 4.2 diatas terlihat bahwa realisasi penerimaan pajak kendaraan bermotor dari tahun 2013-2017 mengalami peningkatan.

Gambar 3

Persentase Realisasi Penerimaan PKB tahun 2013-2017

\section{Realisasi Penerimaan PKB 2013-2017}

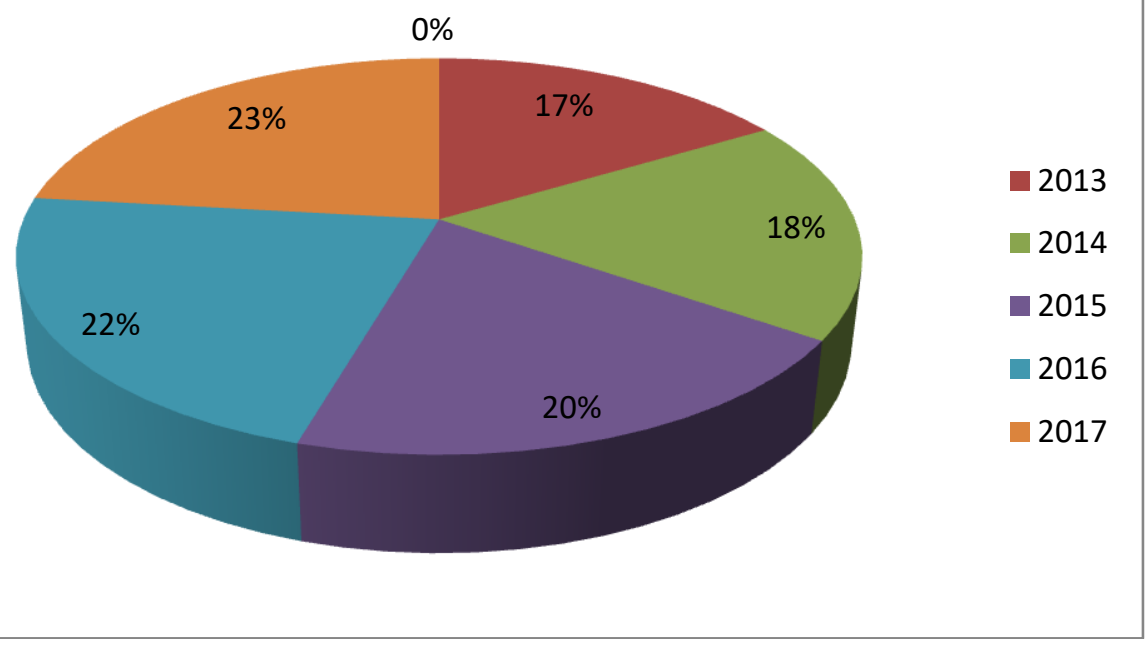

Sumber : Diolah Peneliti 2018

Dari Gambar 3 diatas dapat dijelaskan bahwa persentase penerimaan Tarif Pajak Progresif PKB pada tahun 2013 sebesar 17\% sedangkan pada tahun 2014 sebesar 18\%, sedangkan pada tahun 2015 sebesar 20\%, sedangkan pada tahun 2016 sebesar 22\%, sedangkan tahun 2017 sebesar $23 \%$.

Tabel 4 Perbandingan Antara Target dengan Realisasi Penerimaan Pajak Kendaraan Bermotor Provinsi di Kabupaten Pasaman Barat

\begin{tabular}{|c|c|c|c|c|c|}
\hline \multirow{2}{*}{ No } & \multirow{2}{*}{ Tahun } & \multicolumn{2}{|c|}{ Target } & \multicolumn{2}{|c|}{ Realisasi } \\
\hline & & PKB & BBNPKB & PKB & BBNPKB \\
\hline 1. & 2013 & Rp 14.018.931.000 & Rp 195.393.000 & Rp 14.740.279.300 & Rp 200.329.500 \\
\hline 2. & 2014 & Rp 14.566.188.000 & Rp 173.993.000 & Rp 16.270.280.550 & Rp 207.133.300 \\
\hline 3. & 2015 & Rp 16.112.000.000 & Rp 211.021.300 & Rp 17.831.466.000 & Rp 238.486.950 \\
\hline 4. & 2016 & Rp 18.508.740.800 & Rp 305.054.000 & Rp 19.982.338.400 & Rp 328.359.400 \\
\hline 5. & 2017 & Rp 20.765.473.050 & Rp 415.707.760 & Rp 20.765.473.050 & Rp 415.707.760 \\
\hline
\end{tabular}

Sumber : Samsat Provinsi di Kabupaten Pasaman Barat, 2018

Dari tabel 4 diatas dapat dilihat jumlah yang ditargetkan dan setiap tahunnya perbandingan antara target dan realisasi mengalami peningkatan. penerimaan Pajak Kendaraan Bermotor Jadi dapat disimpulkan penerimaan realisasi penerimaan PKB dan BBNPKB mencaapi

Tabel 5 Realisasi Denda Pajak Kendaraan Bermotor 2013-2017

\begin{tabular}{|c|c|c|}
\hline Tahun & Jumlah PKB yang Tepat Waktu & Total Denda \\
\hline 2013 & 23.336 & 41.666 .000 \\
\hline 2014 & 28.698 & 36.458 .000 \\
\hline 2015 & 32.366 & 30.358 .000 \\
\hline 2016 & 34.424 & 28.576 .000 \\
\hline
\end{tabular}




\begin{tabular}{|c|c|c|}
\hline 2017 & 35.365 & 25.498 .000 \\
\hline
\end{tabular}

Sumber : Samsat Provinsi di kabupaten Pasaman, 2018

\section{Perhitungan Denda Pajak Kendaraan Bermotor :}

Bapak B, Total Baharudin memiliki kendaran bermotor roda empat berupa mobil dan terlambat membayarnya selama 8 bulan, Total pajak Kendaraan Bermotor sebesar Rp 250.000 perhitungannya adalah sebagai berikut :

\author{
Jumlah PKB X Tarif Denda PKB X \\ Lamanya denda \\ Rp 250.000 X 25\% X 8/12= Rp 41.666 \\ Untuk perhitungan denda SWDKLLJ \\ dilakukan oleh Jasa Raharja.
}

Tabel 6Target dan Realisasi Penerimaan Pajak Kendaraan Bermotor tahun 2013 dan tahun 2017

\begin{tabular}{|c|c|c|c|}
\hline Tahun & $\begin{array}{c}\text { Target Tahun } \\
\text { Anggaran (Rp) }\end{array}$ & $\begin{array}{c}\text { Realisasi } \\
\text { Penerimaan (Rp) }\end{array}$ & \% Dari Target \\
\hline 2013 & 14.018 .931 .000 & 14.740 .279 .300 & $105,15 \%$ \\
\hline 2014 & 14.566 .188 .000 & 16.270 .280 .550 & $111,70 \%$ \\
\hline 2015 & 16.112 .000 .000 & 17.831 .466 .000 & $110,67 \%$ \\
\hline 2016 & 18.508 .740 .800 & 19.982 .338 .400 & $107,96 \%$ \\
\hline 2017 & 20.765 .473 .050 & 20.765 .473 .050 & $109,12 \%$ \\
\hline
\end{tabular}

Sumber : Samsat Provinsi di Kabupaten Pasaman Barat, 2018

Dari tabel diatas terlihat jelas bahwa SAMSAT Provinsi di Kabupaten Pasaman Barat melaksanakan asas efisiensi dengan

\section{Penutup}

\section{Kesimpulan}

Berdasarkan hasil pembahsan dan analisa pada bab-bab sebelumnya, maka penulis dapat menarik kesimpulan sebagai berikut:

1. Untuk mengetahui peraturan tarif pajak progresif terhadap wajib pajak kendaraan bermotor Dikabupaten Pasaman Barat sesuia dengan Peraturan Daerah mengenai Pajak Progresif Kendaraan Bermotor dikeluarkan pada Tahun 2013 berdasarkan Peraturan daerah Provinsi di Kabupaten Pasaman Barat No. 8 Tahun 2013 dan mulai dijalankan khusus di SAMSAT Provinsi di Kabupaten Pasaman Barat Pada 1 Januari 2013

2. Sistem dan Prosedur pemungutan Pajak Kendaraan Bermotor pada SAMSAT Provinsi di Kabupaten Pasaman Barat memiliki tahaptahap, mulai dari pendaftaran, penetapan, pembayaran sampai ke tahap pengesahan.

3. Pengenaan Tarif Pajak Progresif pada Pajak Kendaraan Bermotor cukup baik, dimana penerimaan pajak kendaran bermotor ditahun 2013 sampai 2017 telah melebihi target yang ditetapkan berdasarkan "The Four Maxims" masih dianggap relevan, yaitu asas-asas pemungutan pajak yang dikemukakan oleh Adam Smith yaitu diantaranya adalah kesamaan dan keseimbangan (equality), kepastian hukum (certainly), asas ketepatan waktu (convenience of payment), dan asas efisiensi (economic of collection).

4. Mengetahui Tingkat Pertumbuhan Tarif Pajak Progresif pada Pajak Kendaraan Bermotor menunjukkan besarnya presentase pertumbuhan penerimaan pajak kendaraan bermotor dari tahun ke tahun mengalami peningkatan.

\section{Saran}

Saran yang dapat dikemukakan oleh peneliti agar lebih dapat meningkatkan penerimaan dari pajak progresif kendaraan bermotor diantaranya adalah sebagai berikut:

1. Pihak SAMSAT Provinsi di Kabupaten Pasaman Barat harus lebih memberikan pemahaman terhadap pengenaan Tarif pajak progresif ini agar masyarakat 
tidak bingung ketika membayar pajak yang lebih tinggi dari biasanya.

2. Untuk mempermudahkan dan mempercepat pelayanan SAMSAT Provinsi di Kabupaten Pasaman Barat perlu dilakukan penambahan loketloket pembayaran sehingga tidak terjadi penumpukan antrian yang terlalu banyak, agar pelayanan menjadi efektif dan efisien.

3. Sebaiknya pihak SAMSAT memberikan informasi melalui brosur atau media social tentang informasi pembayaran tarif pajak secara progresif.dan pembayaran secara online segera diterapkan untuk memudahkan Wajib Pajak dalam melakukan pembayaran

4. Sebaiknya pencatatan terhadap pajak progresif ini dipisahkan agar dapat diketahui kontribusi pajak progresif kendaraan bermotor terhadap pendapatan dari pajak kendaraan bermotor serta agar diketahui jumlah subjek dan objek pajak progresif ini.

5. Untuk penelitian selanjutnya dapat diharapkan dapat memprluas objek penelitiannya dan periode penelitian dapat diperluas bukan hanya dalam 5 tahun terakhir.

\section{Daftar Pustaka}

Adi, 2012.Penerapan Pajak Progresif Kendaraan Bermotor Dalam Upaya Meningkatakan Pendapatan Asli Daerah. Program Studi Diploma III Perpajakan Fakultas Ekonomi Universitas Sebelas Maret.

Davey, K.J.1988. Pembiayaan Pemerintah

Kurniawan, 2014. Analisis Dampak Sebelum dan Sesudah Penerapan Pajak Progresif Kendaraan Bermotor Dalam Upaya Peningkatan Pendapatan Asli Daerah (Studi Kasus Kabupaten Karanganyar). Program Studi Diploma III Perpajakan
Daerah, Jakarta: Universitas Indonesia Press.

Diana,Sari. 2013. Konsep Dasar Perpajakan. Refika Aditama. Bandung

Dianita, 2012.Pengaruh Pelayanan Terhadap Kepuasan Masyarakat Terhadap Pelayanan Pajak Progresif Kendaraan Bermotor di Samsat Kota Bandung, skripsi Program Serjana Universitas Indonesia.

Ernawati, eka dan Ni Putu Eka Widiastuti.2013. Dampak Pengenaan Tarif Pajak Kendaraan Bermotor Di Provinsi DKI Jakarta.Jurnal Economi Resource Volume 11, No 2.

Fajriani.2013.Pengenaan Tarif Pajak Progresif Pada Pajak Kendaraan Bermotor.Jurnal Vol 1 No 2. Universitas Surabaya. Surabaya. Tahun 2017.

Febriati.2011.Analisis Sistem Pengendalian Pemungutan Pajak Kendaraan Bermotor Dalam Peningkatan PAD pada Dispenda Kota Singkawang.Jurnal Eksos Volume 7, No 2.

http://pajakonline.net/pengertia n-pajakprogresif, Pengertian Pajak Progresif, (online, di akses 22 Desember 2015).

http://www:informasi-pajak (online), Answar.diakses 12 februari 2016.

http://djafa.org/infosamsat-pajak-progresifkendaraan-bermotor/.

http://www.kerjanya.net/faq/4256-pajakprogresif-atas-pajak-kendaraanbermotor.html, Pajak Progresif atas Pajak Kendaraan Bermotor, (Online, di akses 7 November 2014).

Irwanto, Rudi. 2015. Analisis Penerapan Pajak Progresif Terhadap Wajib Pajak Kendaraan Bermotor pada SAMSAT Kota Makassar.skripsi Program Serjana Universitas Hasanuddin Makassar

Fakultas Ekonomi Universitas Sebelas Maret.

Mardiasmo, 2013. Perpajakan,(edisi revisi 2013). Yogyakarta: CV.Andi Offset.

Mulyadi.2001.Sistem Akuntansi.STIE YKPN,edisi ke-3.Yogyakarta.

Nugraha,Agung Harist. 2012. Penerapan Pajak Progresif Terhadap Wajib Pajak Kendaraan Bermotor 
Berdasarkan Peraturan Daerah Jawa Timur Nomor 9 Tahun 2010 Tentang Pajak Daerah (Studi di Kantor bersama SAMSAT Malang Kota). Jurnal Ilmiah. Universitas Brawijaya.Malang.

Saidi, Muhammad Djafar. 2010. Pembaruan Hukum Pajak.Jakarta:Rajawali Pers.

Siahaan, 2006.Pajak Daerah dan Retribusi Daerah. Jakarta: PT.Raja Grafindo Persada.

Sutedi, 2010. Pajak Daerah. Jakarta:Sinar Grafika.

Suprianto, Edy. 2011. Perpajakan di Indonesia, edisi pertama, cetakan pertama, Penerbit : Graha Ilmu, Yogyakarta.

Sugiyono, 2010.Metode Penelitian Kualitatif Kuantitatif dan R\&D. Alfabeta. Bandung.

Waluyo, 2011. Perpajakan Indonesia, Edisi 10.Selemba Empat:Jakarta.

Yunita Sari, Komang.(.2017). Analisis Dampak Penerapan Pajak Progresif Pada Kendaraan Bermotor Roda Empat terhadap Tingkat Penjualan Mobil Baru Di Kecamatan Buleleng.E-Jurnal S1 AK Universitas Pendidikan Ganesha.Volume 7 No 1 Tahun 2017.

Yunus, Abdul Thalib. 2010. Analisis Kontribusi Pajak Kendaraan Bermotor Terhadap Pendapatan Asli Daerah pada Kabupaten Bone Bolango Di Provinsi Gorongtalo. Jurnal Economic Resaurces Volume 11,No 4. 